\title{
How to Improve Students' Physical Quality
}

\author{
Jianzhen Huang, Qing Li \\ Nanchang Institute of Science \&Technology,Nanchang 330108,China
}

Key words: students; physical quality; current situation; measures

\begin{abstract}
In the current education stage, students' physical quality can not keep up with the development of society. The body is the capital of revolution. Especially for the contemporary students, they are the future pillars, Need a physical fitness to match their development.. The students' physical quality is affected by many factors. This paper analyzes the physical quality of the contemporary students and puts forward some solutions. Physical quality as the hardware of body, people do other things on the basis of a healthy body. There is no denying that people's physical quality is very important. But for the students, because most of the students in the school for a long time, the Chinese style education often only pay attention to the students' academic achievement, the students' physical quality is often ignored. In the long-term education, students' physical quality has not get attention. The quality of contemporary students is not high.
\end{abstract}

\section{Introduction}

Our school does a test for the freshman's physical fitness every year. Many schools examine the physical quality of students. The main examination project of the physical quality of students include the height, weight, vital capacity and grip strength, standing long jump, running etc.. In these tests, the physical quality of students is not satisfactory. And showing a decreasing trend year by year. This caused the relevant departments of the state concerned about the physical quality of students. China's sports department also vigorously promote sunshine sports. Its purpose is to improve the physical quality of students. However, after the implementation of these measures, it has little effect. In the school sports meeting, there have been students sudden death phenomenon in the middle and long distance running events. These problems also caused the attention of the school. Many colleges and universities do not take the middle distance race in the games in order to avoid problems with students. The reform of physical education for students in colleges and universities. In these measures, some of the students' physical quality is restricted.

\section{Factors affecting the improvement of students' physical quality.}

Examination oriented education and people's sports consciousness is weak. One of the most important factors that affect the students' physical quality is the Chinese education. Because of the influence of educational thought for a long time. Many parents give their children the traditional ideas are good reading, ignoring the physical quality of students. In the education of students, the proportion of education is very low, in the high school stage of the students, due to the impact of the college entrance examination. Many high schools ignore physical education, do not offer physical education, or change physical education into other courses. In high school and junior high school to promote physical exercise often stays in form. In the education of students, the 
long-term physical exercise reduces the physical quality of students. So that students in the important period of physical development has not been fully exercise.

Physical education emphasis on hobbies, do not attach importance to physical quality. When the nation is promoting sports level. Many colleges and universities are active in physical education reform. Because there is no high school pressure on students. Many colleges and universities in the creation of the students' sports class, the students' interests in the first place. In some colleges and universities, such as billiards, golf and other sports courses. The creation of these physical education courses has attracted the attention of students. However, they do not take into account the physical needs of students. Ignore the actual receive effect to the students. This is also a factor in the current decline in physical fitness of students. This is also a factor in the decline of students' physical fitness.

Sports venues can not meet the needs of exercise. College sports hardware facilities is also an important factor affecting the physical quality of students. In the physical exercise of students, one of the factors that hinder students' Physical Education curriculum. With the rapid development of China's economy, many colleges and universities are actively promoting their level of sports venues. Efforts to provide students with a good physical condition. However, the existing facilities can not meet the needs of students' physical training. Most universities will provide the badminton hall, table tennis hall and other venues. But these venues are usually charged at the time of the student's exercise. It is also an economic burden for students.

Lack of reasonable and effective assessment methods. In Chinese schools, students are from all corners of the country. Students from different regions often have great differences in physical fitness. In the assessment of physical quality of students, the lack of a mature evaluation system which can effectively evaluate the physical quality of students. In the evaluation of school physical education curriculum, it is decided by the teacher, the evaluation of sports results are lack of objectivity, lead to can not the correct evaluation of the students' physical quality. Can not be targeted to improve the physical quality of students.

\section{Measures to improve students' physical quality}

Cultivating students' interest in learning. As everyone knows, the interest is the best teacher, forcing the students blindly, let students learn in an oppressive environment in teaching can not achieved great effect, moreover, it is likely to make the students dislike learning and give up learning. Many studies have proved that stimulating students' interest will improve students' initiative and learning efficiency, and the teaching quality will also be improved. Therefore, in order to promote students to learn physical education, the first thing to do is to innovate the teaching methods, the idea of trying to stimulate students interest in learning sports. So how to stimulate the interest of students? On the one hand, teachers should communicate with students, full and comprehensive understanding of students' ideas, looking for students' real needs, as far as possible to meet the needs of students appropriate and reasonable in everyday teaching process, to attract the attention of students, stimulate their interest, thus consciously into the study of sport. From the physiological, psychological and other aspects of care for students, the value of students, enhance their confidence in learning sports, so that they become the main body of the classroom, to fully mobilize their initiative. On the other hand, teachers should actively reform and innovation of teaching methods, changing teaching concept, change with the development of the times, so that the traditional, boring teaching methods become innovative, personalized, practical direction. The teaching method of suiting measures to local conditions, take in the sports teaching is very 
necessary. Because each student's physical strength is different, each student's own advantage is also different, teach students in accordance with their aptitude to improve the learning efficiency, to help every student to strengthen physical exercise, improve physical fitness. The teacher can't give up every one of the students, for the original excellent students to strengthen the difficulty and intensity of training, let them to the next level, for those relatively poor students, to encourage them, while simplifying the content of the training, from basic start, enhance their self-confidence. Let each student in the process of learning to gain some sports, and thus love sports.

Rational use of theoretical teaching to improve students' awareness of participating in physical exercise. Unlike most subjects, physical education are consisted of two parts, in addition to practice, there are theoretical part. The role and significance of physical exercise, physical exercise definition method, physical training to students through the teaching theory, the rational use of theory teaching to promote students' understanding of the sport, aware of the importance of physical exercise. Therefore, teachers should realize the importance of theoretical teaching, give full play to the role of theoretical teaching, improve students' awareness of learning sports, and lay a good foundation for practical teaching.

Improve the teachers' quality, and teach students scientifically exercise means. Teachers should enrich their knowledge and improve their quality in the process of imparting knowledge. Teachers should set an example In skills, get high standards, high goals, strengthen physical exercise, try to make his every move can be standardized, skilled, influence their students with their own practical action, promote student learning, improve students' learning interest. Only in the ability of teachers to improve, in order to better explain to the students, to promote students' understanding of sports knowledge, in order to ensure the accuracy of the knowledge imparted to the students. In teaching methods,they should actively innovation, study teaching methods from home and abroad, take the essence and discard the dross, enrich their teaching methods, relevant content always pay attention to teaching reform, trying to find the direction of education reform, to keep up with the pace of the development of the times. Change their backward teaching ideas, the courage to reform and innovation, the education sector will be innovative, practical teaching methods introduced into the classroom, so that students feel the charm of learning sports. At the same time, teachers can not ignore the relevant content of the material, based on the textbook for this, appropriate extension, combined with the characteristics of their students, linked to real life, through some lively activities, active classroom atmosphere, let students learn in a happy atmosphere, direct the students learning fun. Along with the development of new media, by means of science and technology aided teaching, such as adding multimedia intercourse, lead the students to watch the related video, it can make the knowledge more vivid, helps students understand the knowledge, improve the efficiency of the classroom. In a word, it is never too late to learn, learning knowledge is the world without end, there is no time limit, teachers should constantly improve their own quality, in order to better teach students. Teachers are only responsible for the work, strict demands on themselves, in order to allow students to convince, in order to influence students, improve students' interest in learning.

Select the most direct project, the reasonable choice of teaching content. The content of sports teaching is more extensive, on the one hand, especially the introduction of the new curriculum, increase the kinds of teaching materials, expanding the scope, in this way, for teachers there are both advantages and disadvantages, help the teachers according to the demand characteristics of the students, to choose the most suitable textbooks as teaching content, arouse students attention,on the other hand, expand the scope of the teachers also increased the difficulty of textbooks, caused the disorder of choice. The choice of teaching material is a task that teachers can 
not ignore. The teaching material is closely related to the content of physical education in the future. In addition, we should choose the most direct project, most conducive to improve the physical quality of the students in the training project, related training for the students, try to improve the efficiency of learning, use all the time and resources to the greatest extent. At the same time, we should pay attention to the comprehensiveness of the project and improve the comprehensive quality of the students.

\section{Conclusion}

To sum up, physical exercise is conducive to improve our physical fitness, have an important impact to our study and life.Young are strong, the country strong, students as a new generation of young people, the role should not be overlooked to the future development of a country. Therefore, as a sports teacher, to enhance their sense of responsibility, in order to improve the students' physical quality, promote the healthy growth of students as their responsibility, to play its biggest role.

\section{Reference}

[1] Liu Shihai, Liu Jinsong. An Empirical Study on the intervention of College Students' physical quality [J]. Journal of Wuhan Sports Institute, 2016,50 (4): 90-94

[2] Liu Ying, Fu Liang. An analysis of the reasons for the continuous decline of physical quality of students in China [J]. Journal of Anhwei Normal University (NATURAL SCIENCE EDITION), 2012,35 (3): 280-282

[3] Shen Jianfeng, Pang Yuanning, et al. Experimental study on the effect of the head teacher of middle school on the physical and mental health of students and KAP [J]. Journal of Chengdu Sport University, 2013,39 (4): 91-94

[4] Fu Xuming. The students' physical quality of vital national survival -- on the decline of students' physical quality [J]. Journal of Anhwei Normal University (NATURAL SCIENCE EDITION), 2012,35 (4): 400-404 